\title{
Past victories, uncertainty, and reflections on the present and progress in the future
}

\author{
TAKashi Sugimura* \\ National Cancer Center, 1-1, Tsukiji 5-chome, Chuo-ku, Tokyo 104-0045, Japan
}

\section{Prologue}

Gastric cancer has been the predominant cancer in many countries, but its incidence in developed nations has sharply declined. This decrease is related to improvements in the diet, with more balanced nutritional value. Further, the convenient preservation of food with electric refrigerators played a role in reducing the use of salt and nitrite. There has been a continual gradual decline in the incidence of gastric cancer over the past several decades in Japan; in 1993 the incidence of lung cancer in men exceeded that of gastric cancer. However, worldwide, gastric cancer has the greatest mortality rate of any cancer [1].

\section{Carcinogenic processes}

There has been considerable dispute concerning the carcinogenic mechanisms of gastric cancer. Gastric ulcer was once considered to be a crucial precursor lesion for gastric cancer. Meanwhile, many histopathologic studies revealed that chronic atrophic gastritis and intestinal metaplasia were closely related to precancerous conditions, especially that of the intestinal type of gastric cancer, which often arises from the pyloric and antral regions. The diffuse type of gastric cancer, being more undifferentiated or scirrhous, is distinguished from the intestinal type in many aspects, including its carcinogenic mechanisms [2,3].

Recent progress in molecular biology has revealed that the genetic alterations in the two types of gastric cancer are somewhat different. For instance, amplifica-

Received and accepted for publication on Aug. 18, 1998

* President Emeritus, National Cancer Center tion of the HER2/C-ERBB2 gene was often found in the intestinal type of gastric cancer, while amplification of the $K-S A M$ gene was frequently found in the diffuse type. Alterations of many other cancer-related genes, including those of $M E T(H G F R)$ and the telomerase gene, were reported to occur in a step-by-step fashion, as reported for colon carcinogenesis [3]. Advances in our knowledge of the histopathology of carcinogenic events in gastric cancer have enabled the diagnosis of many gastric cancers at an early stage. Carcinoma in situ is now often found in biopsy specimens obtained gastroendoscopically.

\section{Diagnosis and treatment}

The introduction of double-contrast radiography led to revolutionary progress in the 1960s. Early gastric cancer was efficiently detected by endoscopy with a fiberscope, while, recently, electronic endoscopes with a chargedcoupled device on the distal end have been used. Diagnosis based on endoscopic findings and biopsy specimens is now common. However, as with most other malignancies, the borderline between precancerous change and the earliest stage of gastric cancer depends partly on the diagnosis of individual pathologists. There is also an "East versus West" cotroversy regarding the diagnosis of early gastric cancer [4]. Molecular diagnosis may help, but would not be precise because of the enormous number of possible combinations of altered genes [5].

In countries other than Japan, mass-screenings for gastric cancer by indirect radiography and endoscopy have not yet been widely adopted. Many countries need improvements in the laborious diagnostic procedures and also need to be aware of false-positive and falsenegative cases.

Various surgical procedures involving extensive lymphadenectomy were developed to reduce the rate 
of recurrence, but the significance of the extent of lymphadenectomy has yet to be proven objectively. The safety of the more extensive surgical procedures has been improved by improved postoperative care [6].

Issues such as misdiagnosis and of unnecessary surgery for gastric cancer raise concerns, as with other cancers. For mass-screening, detection methods for high-risk groups need to be enhanced; as well as careful radiography and endoscopy, other practical measures are necessary. Pepsinogen I and antibody against Helicobactor pylori in sera are candidates for practical measures to be considered [7].

\section{Causation and prevention}

Atrophic gastritis was understood to represent a likely precancerous lesion. Many chemicals were tested in experimental animals as potential gastric carcinogens, with negative outcomes in most instances. However, the nitroso compounds, $N$-methyl- $N^{\prime}$-nitro$N$-nitrosoguanidine (MNNG), a potent mutagen, and $N$-methyl- $N$-nitrosourea (MNU), are now being used widely for the development of experimental gastric cancers with high reproducibility, and these compounds are associated with the production of atrophic gastritis in rodents and dogs. It has been proven that gastric cancer was produced by damage to DNA or alterations in cancer-related genes [8]. In fact, many somatic genetic alterations have been found in human gastric cancers, as described earlier. Because MNNG and MNU do not occur naturally, various other nitroso compounds and other mutagens in food have been examined as possible natural causative substances, but their contributions are not yet proven. Recently, the heritable nature of gastric cancer was shown in familial gastric cancer in New Zealand. The E-cadherin gene, which codes for one of a class of adehesion molecules, was altered in the germlines [9].

Meanwhile, Helicobactor pylori, which was first described about a century ago, was "rediscovered" after successful in-vitro culture. Helicobactor pylori and cancer occurrence seem to be related through the mechanism of oxidative agent production. Eradication of the bacteria by proton-pump inhibitors and antibiotics could reduce chronic gastritis, probably resulting in the prevention of gastric cancer. There is a view that Helicobactor pylori infection was a part of normal existence during our long human history. The incidence of Barrett's esophagus adenocarcinomas and adenocarcinomas at the junction between esophagus and cardia is, however, slowly increasing despite hygienic conditions without Helicobactor pylori infection [10]. Although cancer prevention is more complicated than once thought, a balanced diet, less salt, and vegetables rich in vitamins and natural antioxidants are being recommended. The inclusion of more vegetables and fruits rich in vitamins in the diet is a practical measure for chemoprevention [11].

Further improvements in the understanding of carcinogenic events/mechanisms, through molecular studies, should facilitate diagnosis and mass-screening. Endoscopic surgical treatment of early gastric cancers is less invasive, less costly in medical term, and requires a shorter hospital stay [12].

Preventive measures against gastric cancer will shift its onset to a much higher age group, and eventually it is to be hoped that the onset of gastric cancer will be delayed until the end of the human life span. Indeed, in Japan the term, "Tenju gann" or "natural-end-of-lifespan cancer" is being proposed for such an entity [13].

\section{Epilogue}

The author wishes to offer his congratulations on the establishment of this new international journal specific to gastric cancer - the official journal of the International Gastric Cancer Association and the Japanese Gastric Cancer Association. By providing vivid and efficient means for exciting worldwide information exchange, the journal should aid researchers and gastric cancer clinicians.

\section{References}

1. Coleman MP, Esteve J, Damiecki P, Arslan A, Renard H, editors. Stomach. In: Trends in cancer incidence and mortality, IARC Scientific Publications No. 121. Lyon: International Agency for Research on Cancer, 1993: pp 193-224.

2. Laurén P. Histogenesis of intestinal and diffuse types of gastric carcinoma. Scand J Gastroenterol 1991;26(Suppl 180):160-4.

3. Tahara E. Genetic alterations in human gastrointestinal cancers. Cancer 1995; 75: 1410-17.

4. Schlemper RJ, Itabashi M, Kato Y, Lewin KJ, Riddell RH, Shimoda $\mathrm{T}$, et al. Differences in diagnostic criteria for gastric carcinoma between Japanese and Western pathologists. Lancet 1997;349:1725-9.

5. Sugimura T. An overview of cancer prevention. Eur J Cancer Prevention 1996;5(Suppl 2):1-8.

6. Maruyama K, Sasako M, Kinoshita T, Okajima K. Effectiveness of systematic lymph node dissection in gastric cancer surgery. In: Nishi M, Ichikawa H, Nakajima T, Maruyama K, Tahara E, editors. Gastric cancer. Tokyo Berlin Heidelberg: Springer-Verlag; 1993: pp 293-305.

7. Parsonnet J, Samloff IM, Nelson LM, Orentreich N, Vogelman $\mathrm{JH}$, Friedman GD. Helicobacter pylori, pepsinogen, and risk for gastric adenocarcinoma. Cancer Epidemiol Biomarkers Prev 1993;2:461-6.

8. Ohgaki H, Sugimura T. Experimental gastric cancer. In: Sugimura T, Sasako M, editors. Gastric cancer. New York: Oxford University Press; 1997:pp73-86. 
9. Guilford P, Hopkins J, Harraway J, McLeod M, McLeod N, Harawira $\mathrm{P}$, et al. E-cadherin germline mutations in familial gastric cancer. Nature 1998;392:402-5.

10. Blaser MJ. Science, medicine, and the future: Helicobacter pylori and gastric diseases. BMJ 1998;316:1507-10.

11. Nomura A. Stomach Cancer. In: Schottenfeld D, Fraumeni J Jr, editors. Cancer epidemiology and prevention. 2nd ed. New York: Oxford University Press; 1996: pp 707-24.
12. Tada M, Karita M, Yanai M, Yanai H, Kawano H, Shigeeda M, et al. Treatment of early gastric cancer using strip biopsy, a new technique for jumbo biopsy. In: Takemoto T, Kawai K, editors. Recent topics of digestive endoscopy. Tokyo: Japan Excerpta Medica; 1987: pp 137-42.

13. Kitagawa T, Hara M, Sano T, Sugimura T. The concept of Tenjugann or Natural-End Cancer. Cancer 1998;83:10615. 